\title{
Rocket Science in a Virtual World
}

\author{
Barry Spencer \\ Bromley College
}

\section{Rationale}

As a partner college of the University of Greenwich, Bromley College runs Foundation Degrees in Software Development and Network Computing. As part the programme, students complete a major Software Development project in Years 1 and 2. The project theme for the academic year 2014-15 was Rocket Science, where students were required to produce a desktop program capable of modelling the flight of a single-stage rocket.

In education, virtual worlds provide unique learning opportunities for accurate/real contexts and activities for experiential learning, simulation, modelling of complex scenarios and social interaction that may not be experienced in other learning modalities (Atkinson, 2009).

As students' understanding of the mathematics, physics and technology relevant to rocketry may not be assumed from their prior compulsory education or experience, I decided that the affordances of a virtual world such as OpenSimpulator/SecondLife would be able to counter any deficit via an immersive learning experience.

The benefits to students have been twofold: first, in using the medium, they acquired the knowledge, understanding and competence to complete the task; second, they experienced the advantages of collaborative, virtual, social, synchronous communication afforded by the visual learning styles of the $3 \mathrm{D}$ environment.

A sense of historic realism was injected into the project by the inclusion of rocket models based on actual UK designs.

The virtual learning aspect for the project took place over a two-week period.

\section{Target audience}

The cohort was comprised of 26 post 18 students, within which group there were two students with statements for learning needs, one for dyslexia and the other for pervasive learning disorder.

\section{Resources}

Given the particular nature of the exercise, the students were provided with resources additional to the standard desktop setup, including the virtual world itself, running in Open Simulator V-0.8, and a suitable virtual word viewer.

\section{Learning and Assessment}

In completing the virtual world project, the students gained a working appreciation of the fundamentals of rocket technology and were able to calculate the flight profile of a singlestage model rocket, supported by the results of in-world formative assessment using chat logs and notecards, and by notecards only for summative assessment. (Please refer to the 
Evaluation section for outcomes.) These tools are, I feel, consistent with items identified within the six sources of evidence and supporting documentation required by Yin (2003).

\section{Learning space design}

Virtual learning would be presented as a signposted, linear, walk-through workflow series of activities, from Orientation to Simulation, as shown below in Figure 1.

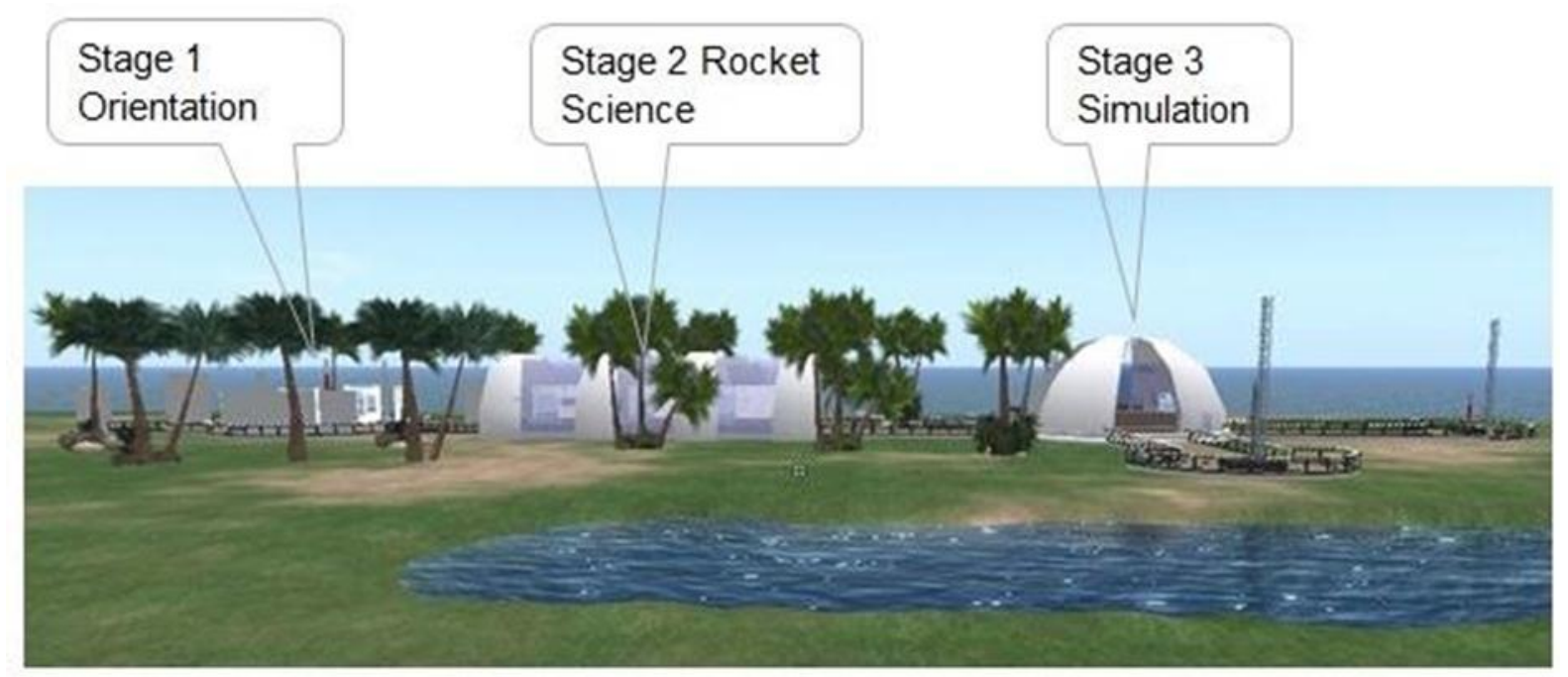

Figure 1: ‘ Only Rocket Science' Learning Flow

\section{Tutor's role}

The project began with a tutor-guided walk-through, after which students were able to plan and manage their own learning. Throughout the session, text chat logs, notecard feedback, reflection and questions using IM were reviewed.

\section{Potential hazards for the project}

Technically, there might have been problems related to the availability to the students of suitable hardware, including broadband connection and graphics card compatibility. However, as the project was run during term time, students were able to make full use of college facilities.

\section{'Only Rocket Science', Entry Point}

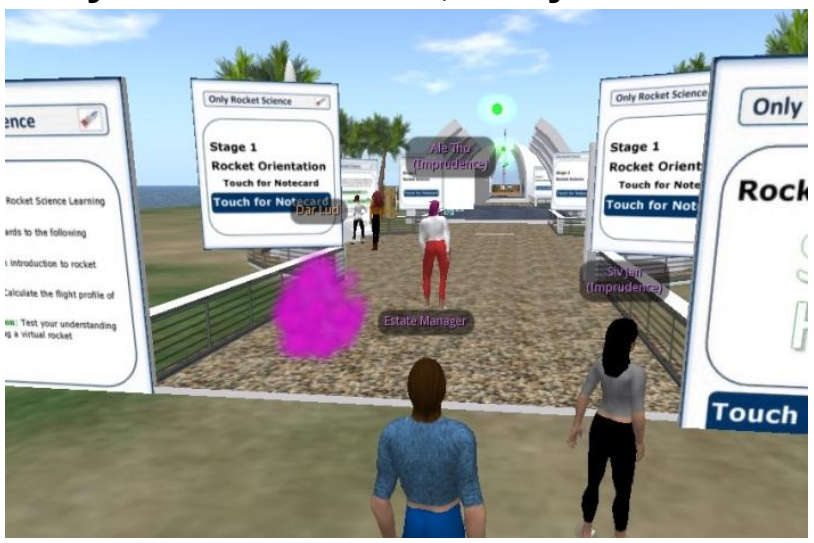

At entry, the students were invited to accept a notecard explaining the learning sequence; then, as they moved on to subsequent stages, notecard dispenser boards prompted them to accept further notecards explaining the requirements of that particular stage. See Figure 2.

Figure 2: Entry Point 


\section{'Only Rocket Science', Stage 1 - Orientation}

The learning aims for the stage are outlined in the notecard:

You should become familiar with the following components and their use: nose cone, body, fins, parachute, shock cord, wadding, engine assembly

The formula $\mathrm{f}=\mathrm{ma}$

Understand engine coding, i.e. A8-3

A - The Total Impulse (power measured in Newton-seconds). The class A engine value is 2.5

8 - The average thrust of the rocket engine during its burn time, also in Newton seconds

3 - Eject delay - the number of seconds following engine burnout until the parachute ejection charge fires

You should also be familiar with the idea of initial engine weight and fuel weight, as we shall be using these values to determine average engine weight

\section{'Only Rocket Science', Stage 2}

This stage is made up of three tasks that cover Boost, Coast and Recovery phases of the rocket's flight. The stages are presented as a signposted, linear, walk-through series of activities, carried out using similar workflows that are presented as: introduction notecard boards, exercise boards, calculator boards and a drop box. See Figure 3 .

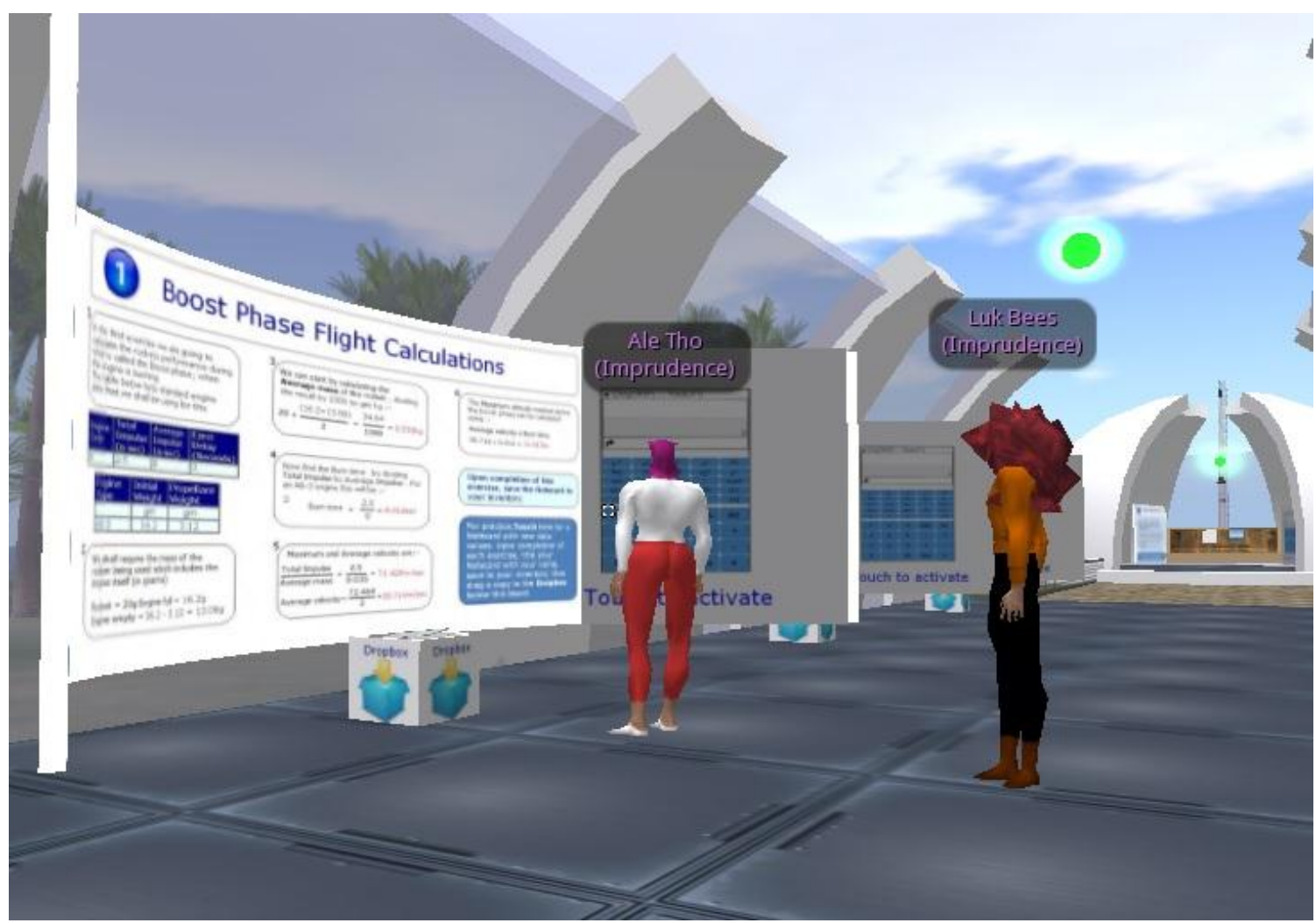

Figure 3: Boost, Coast and Recovery Phases 


\section{Example: Stage 2, Task 1 (The Boost Phase)}

1: The notecard board (on the left in the Figure 4 image below) introduces the task, dispensing a notecard for the students to work through (using the in-world online calculator) the example calculations shown on the adjoining exercise board and to record their results.

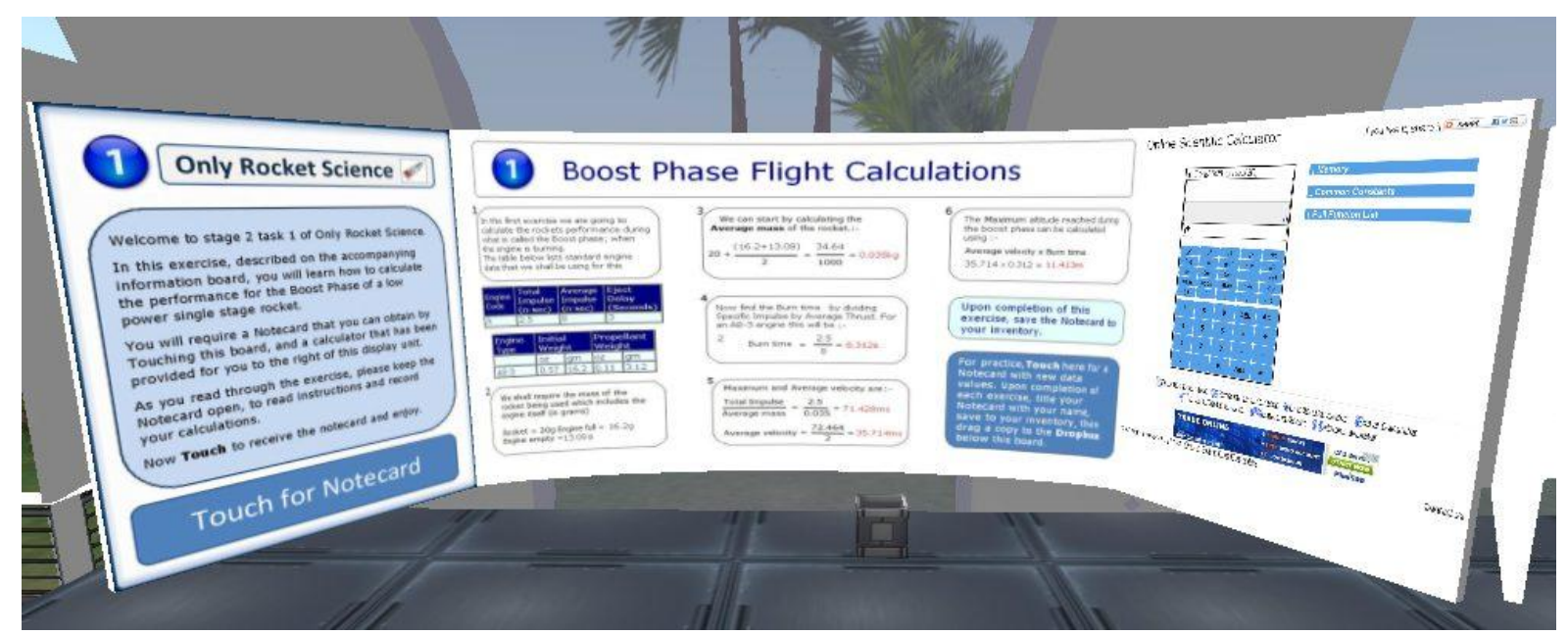

Figure 4: Boost Phase Notecard Dispenser

As this is a formative exercise, the students simply worked through the example shown on the board, reproducing results on their own notecard.

2: Upon completion, the notecard was named, saved to inventory and dragged to the dropbox.

3: The exercise board prompted students to take another notecard containing a new, unworked, problem.

4: Upon completion, that notecard was named, saved to inventory and dragged to a dropbox for summative assessment.

Each notecard requests students to reflect on the learning experience. See Figure 5.

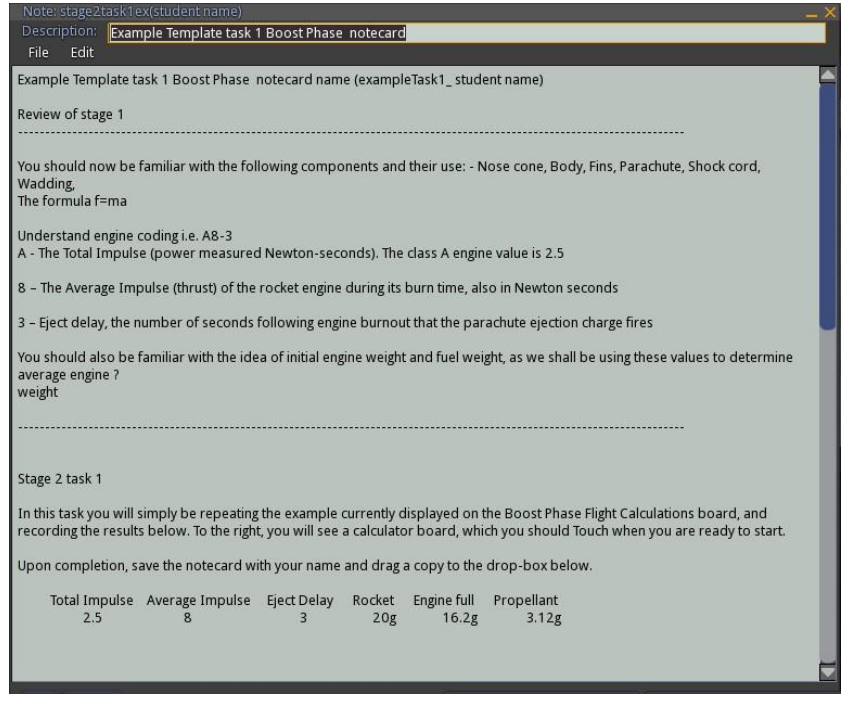

Figure 5: Completed Notecard
Was the task made clear?

Did the Rocket Orientation exercise prepare you enough, or would you like to revisit?

The quality of the images on the display board was satisfactory.

Did you complete the task alone or with other students?

Was carrying out the actual exercise beneficial to your overall understanding? How would you describe working with other avatars?

What did you like most? What least? How would you improve the learning stage? 


\section{Example: Stage 3 (The Simulation)}

The final simulation stage draws the together the work of the previous stages. It presented the students with a full set of flight-profile calculations, dispensed once again from the notecard board. Upon completion, the notecard was saved and a copy dragged to the dropbox. Students could then check their results by launching a rocket: touching the green button at the centre of the launch console table produces a series of drop-down options prompting for input parameters, after which a soundscape introduces the countdown and launches the rocket. See Figure 6.

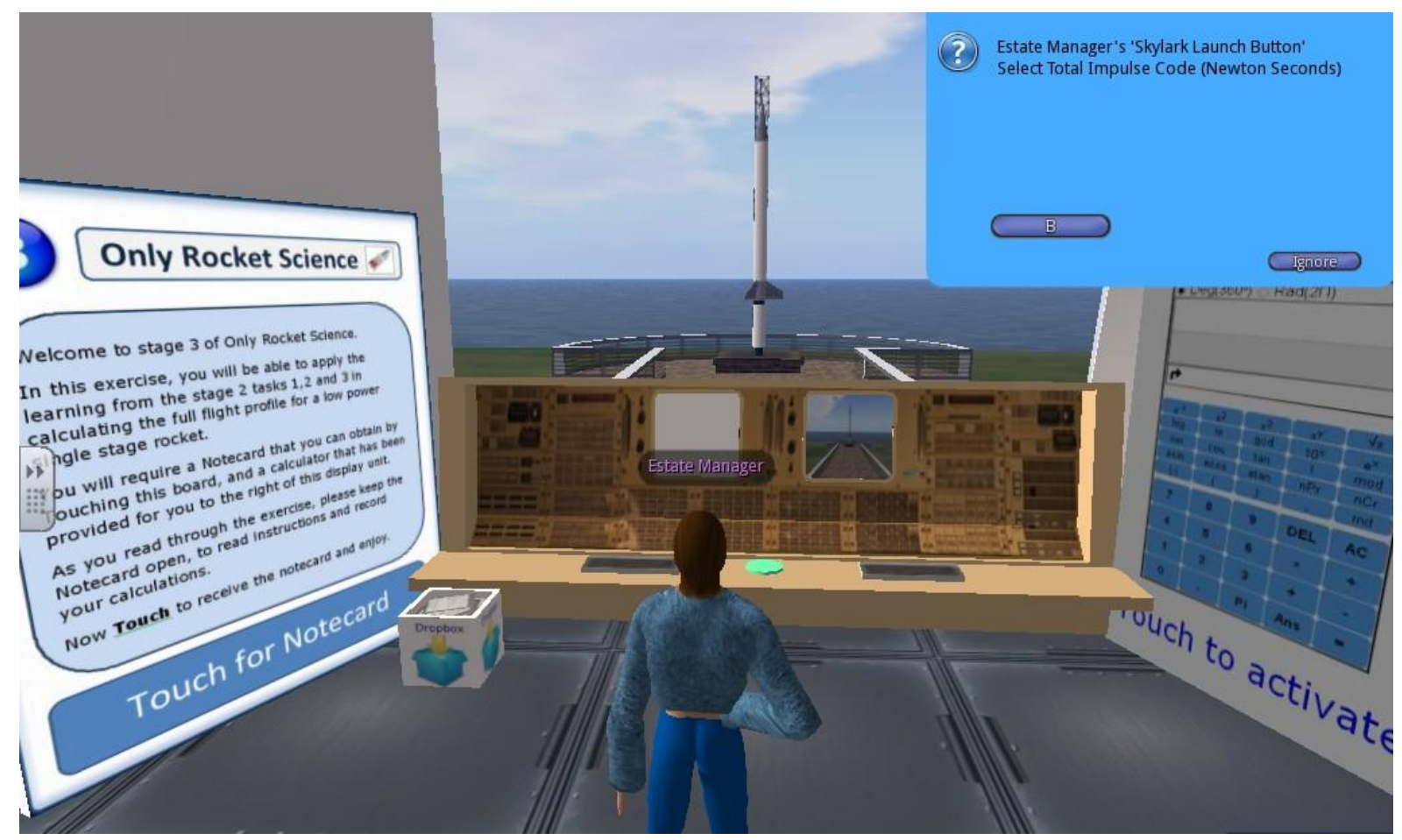

Figure 6: Rocket Simulation

Eventually, the rocket descends on a parachute return, shortly after which the calculated flight profile is displayed for comparison.

\section{Theoretical underpinning (the learning space)}

Since students inevitably experience a range of emotions during any eLearning session, comfort is considered important in leveraging affordances and capabilities. Findings from Saleeb and Dafoulas (2010) suggest that irritation and subsequent boredom become the most undesirable emotions and that colour plays an important role, with white and light-blue evoking the highest number of positive emotions, specifically comfort and consequent attentiveness.

Structural architecture and landscaping in the design were constrained to fall in line with the results from various research projects investigating the impact of a learning environment on learning itself (Saleeb and Dafoulas, 2010; Dickey, 2004). As a result, the build features large open areas to facilitate flying, the inclusion of water and greenery, landmarks, simple modern buildings with no over-decoration or imaginative enhancement, wide corridors to aid avatar movement and the arrangement of learning subspaces consistent with expected use. 
Where buildings are used to accommodate an activity, the ratio of wall to window falls within the recommended 50:50 ratio recommended by Minocha and Reeves (2009). In general, avatar movement is significantly improved by using dynamic textures and rhythmicallyrepeated elements in paths (Bridges and Charitos, 2001) and avatar rotation is avoided, in order to improve ease of orientation and navigation in the space (Charitos, 1999). An apparent strong preference for good lighting led to open-topped buildings, without the imposition of ceilings; as circular buildings were also favoured, they have been deployed in two of the three sub-spaces.

\section{Theoretical underpinning (pedagogy)}

The learning space has been designed to support social constructivism as the driver in what is a highly-interactive and participatory environment. Students are able to test their ideas and understanding as they actively engage in real-time simulations and feedback, with tasks that encourage problem-solving and critical thinking (Roussou, 2015). The first task of Stage 2 promotes the construction of knowledge from prior experience of physics at Key Stage 3 or equivalent, drawing upon the individual's unique world experience consistent with the three general principles outlined by Dalgarno (2001) and supported and mediated by the Open Simulator virtual world.

As students are encouraged to collaborate and plan their own learning, I feel the review of the text chat session will reveal evidence of Cognitive, Teaching and Social presence in the emergence of a Community of Enquiry (Garrison et al, 2000) and that the shared, collaborative, goal-directed nature of the activity in turn induces Embodied Social Presence, drawing the participants into a higher level of cognitive engagement (Mennecket and Triplett, 2011). The immersive components of fidelity and adoption of design best practice in a collaborative social space are intended to leverage some or all of five dimensions of presence and co-presence that could lead to a flow, enjoyment, focus and concentration that combine to increase a positive attitude to learning (Choi et al, 2007).

\section{Instructional design constraints}

From a study of the affordances of traditional Instruction design models, it appears that they in general do not offer precise guidance for the process of designing instruction in virtual world environments (Chen, 2010) and, further, that they tend to be process-oriented, static and linear, do not meet user expectations in a virtual world (Hodge and Collins, 2010; Chen et al, 2004) and are viewed by many as based upon outdated approaches to teaching and learning (Soto, 2013). Throughout Soto's (2013) study, which reviewed twenty-eight Instructional Design models, the ADDIE model, with its five phases of Analysis, Design, Development, Implementation and Evaluation, was found to be the most common Instructional Design process (75.4\%) for virtual worlds.

Specifics to learning in a virtual world need to be introduced into any current Instruction Design model if it is to be of real use, something which appears to be addressed by the study's conclusion which states: "ADDIE process presents the necessary methods for guiding the design of elements needed for instruction in virtual world environments" (Soto, 2013, p.369). These may be summarised as:

1. Experience learning by solving a problem that may be encountered in a real-world situation. 
2. Build on what students already know by adapting, modifying, and transforming the virtual world to construct new knowledge as well as to apply existing knowledge to new contexts/situations.

3. Interact in an immersive environment where knowledge is presented in an authentic context.

4. Transfer and apply the in-world learning to everyday life situations.

5. Work collaboratively to undertake tasks, exploring and negotiating with one another to complete the activities and reflecting on their learning along the way.

The second most popular Instructional Design (at 29.5\%) proposes a more refined ten-stage system that I considered to be too detailed for my purposes (Dick et al, 2009).

\section{Instruction strategy}

The analysis component of the ADDIE model identifies the need for an instructional strategy and for this I selected Merrill's First Principles of Instruction. From research, there is convincing evidence that using First Principles of Instruction in education improves both student learning and satisfaction (Frick et al, 2007) by offering explicit guidance for assisting students in both their learning and development (Reigeluth, 1999). I felt that the provision of such guidance would readily accommodate outcome requirements and would fall very much within the scope of my own learning space design for social constructivism.

In reviewing the First Principles, I also felt that using laws of motion applied to real-world rocket vehicles and with real-time feedback, in a staged workflow process building to a complete solution (and drawing upon KS3 experience or equivalent combined with reflection and assessment from notecards) would work well with the Task/Problem-Centred strategy components of Activation, Demonstration, Application and Integration.

\section{Evaluation}

The virtual world work represented a maximum of $15 \%$ of the final assignment grade, giving a final average of $56.46 \%$. During their sessions in the virtual world, students made 171 unique visits and logged 421 lines of conversational chat. Resource activity was logged using a MySQL database which recorded 1302 hits. In Appendix 1, I have included the results of a short post-project survey of students' impressions of using the virtual world for their learning activity.

\section{Conclusion}

This was an extremely worthwhile project which students enjoyed and from which they benefited as Appendix 1 demonstrates the affordances of a 3D virtual world proved to play an important part in the delivery of a specialist topic to a group of students from diverse backgrounds. I intend to develop my ideas for deploying this, a valuable emerging technology that has clearly encouraged and enhanced engagement, enthusiasm and collaboration in an educational setting. 


\section{Appendix 1}

Using the virtual world was fun and exciting

$\begin{array}{lcr}\text { Response } & \text { Average } & \text { Total } \\ \text { neither agree or disagree } & 7 \% & 1 \\ \text { agree partially } & 47 \% & 7 \\ \text { agree completely } & 47 \% & 7 \\ \text { Total } & 100 \% & 15 / 15\end{array}$

I would avoid classes using a virtual world in the future

$\begin{array}{lcr}\text { Response } & \text { Average } & \text { Total } \\ \text { disagree completely } & 67 \% & 10 \\ \text { disagree partially } & 20 \% & 3 \\ \text { neither agree or disagree } & 13 \% & 2 \\ \text { Total } & 100 \% & 15 / 15\end{array}$

Working in a virtual world is an enriching experience

\begin{tabular}{l|rr} 
Response & Average & Total \\
disagree partially & $7 \%$ & 1 \\
neither agree or disagree & $7 \%$ & 1 \\
agree partially & $47 \%$ & 7 \\
agree completely & $40 \%$ & 6 \\
Total & $100 \%$ & $15 / 15$
\end{tabular}


I experienced very few problems in using the virtual world

\begin{tabular}{l|rr} 
Response & Average & Total \\
disagree partially & $7 \%$ & 1 \\
neither agree or disagree & $13 \%$ & 2 \\
agree partially & $33 \%$ & 5 \\
agree completely & $47 \%$ & 7 \\
Total & $100 \%$ & $15 / 15$
\end{tabular}

I often used the virtual world from home during my project

\begin{tabular}{l|rr} 
Response & Average & Total \\
disagree partially & $7 \%$ & 1 \\
neither agree or disagree & $20 \%$ & 3 \\
agree partially & $27 \%$ & 4 \\
agree completely & $47 \%$ & 7 \\
Total & $100 \%$ & $15 / 15$
\end{tabular}

My classmates and I cooperated in completing assignment work in the virtual world

\begin{tabular}{l|rr} 
Response & Average & Total \\
disagree partially & $7 \%$ & 1 \\
neither agree or disagree & $27 \%$ & 4 \\
agree partially & $13 \%$ & 2 \\
agree completely & $53 \%$ & 8 \\
Total & $100 \%$ & $15 / 15$
\end{tabular}


The virtual world was beneficial to my learning

\begin{tabular}{l|rr} 
Response & Average & Total \\
neither agree or disagree & $7 \%$ & 1 \\
agree partially & $40 \%$ & 6 \\
agree completely & $53 \%$ & 8 \\
Total & $100 \%$ & $15 / 15$
\end{tabular}




\section{Reference list}

Atkinson, T. (2009) 'Second LifeTM for educators: Teaching and learning.' TechTrends, 53(3), 30-32. doi:10.1007/s11528-009-0285-7

Bridges, A. and Charitos, D. (2001) 'The Impact of $f$ orm on Movement within Virtual Environments. Automation in Construction. Science Direct. Available at: http://www.sciencedirect.com/science/article/pii/S0926580500000650 ( Accessed 23 Sept 2015)

Charitos, D. (1999) 'Human Spatial Orientation in Virtual Worlds.' In: Ascott, R. (ed.), Reframing Consciousness. Bristol, UK: Intellect Books, ISBN 1-84150-013-5. pp. 223-228.

Chen, C. (2010) Virtual reality (VR)-based learning environment: Design, develop, evaluate. Saarbrücken, Germany: Lambert Academic.

Chen, C. J., Toh, S. C. and Wan, M. F. (2004) 'The theoretical framework for designing desktop virtual reality-based learning environments.' Journal of Interactive Learning Research, 15(2), 147-167. Available from EdITLib Digital Library. (12841)

Choi, Y., Abbott, T., Arthur, M. and Hill, D. (2007) 'Toward a future wireless classroom paradigm.' International Journal of Innovation and Learning, 4. Available at: http://www.academia.edu/1476096/Mobile Learning Attitudes and Effectiveness (Accessed: 23 Sept 2015).

Dalgarno, B. (2001) 'Interpretations of constructivism and consequences for computer assisted learning.' British Journal of Education Technology. 32(2), 183-194.

Dickey, M.D. (2004) 'An architectural perspective for the design of educational virtual environments.' Journal of Visual Literacy, 24, (1).

Dick, W., Carey, L. and Carey, J. O. (2009) The systematic design of instruction (7 $7^{\text {th }}$ edition). Upper Saddle River, NJ: Pearson.

Frick, T., Chadha, R., Wang, Y., Watson, C. and Green, P. (2007) 'College student perceptions of teaching and learning quality.' Educational Technology Research and Development. Available at:

http://www.springerlink.com/content/722jm250401j7l77/fulltext.pdf. (Accessed: 19 June 2009).

Garrison, R., Anderson T. and Archer,W. (2000) 'Community of enquiry.' Available at: http://www.sciencedirect.com/science/article/pii/S1096751600000166 (Accessed: 23 Sept 2015). 
Hodge, E. M. and Collins, S. (2010) 'Collaborative efforts: Teaching and learning in virtual worlds.' EDUCAUSE Review, 45(3), 62-63. Available at:

http://www.educause.edu/ero/article/collaborative-efforts-teaching-and-learning-virtualworlds (Accessed: 23 Sept 2015).

Leshed, G. and McLeod, P.L. (Year) Metaphors for Social Relationships in 3D Virtual Worlds. New York: Cornell University, Department of Communication.

Mennecket, B. and Triplett, J. (2011) 'An Examination of a Theory of Embodied Social Presence in VirtualWorlds'. An Examination of a Theory of Embodied Social Presence in Virtual Worlds. Decision Sciences publication Volume 42 Number 2

Minocha, S. and Reeves A.J. (2009) Interaction design and usability of learning spaces in 3D multi-user virtual worlds. Pune, India: Human Work Interaction Design.

Roussou, M (2015) 'Learning by Doing and Learning Through Play: An Exploration of Interactivity in Virtual Environments for Children.' University College London (UCL). Available at: http://en.wikipedia.org/wiki/First Principles of Instruction (Accessed: XX Month Year)

Reigeluth, C.M. (1999) 'What is instructional-design theory and how is it changing?' In: C. Reigeluth C.M. (ed.), Instructional-design theories and models: A new paradigm of instructional theory, 2, 5-29. Mahwah, NJ: Lawrence Erlbaum Associates, Inc.

Saleeb, N. and Dafoulas, G. (2010) 'Whose turn to renovate the class today? Analogy between Impact of Architectural Design Characteristics of Learning Spaces on Learners in the Physical World and 3D Virtual World.' Journal of Virtual Studies (JVS), 1 (1), 72-89.

Saleeb, N. and Dafoulas, G. (2010) Affordances and Constraints to EW-Learning: Role of Architecture in 3D Learning Space Digital Design. London: Middlesex University.

Soto, V,J. (2013) Which Instructional Design Models are Educators Using to Design Virtual World Instruction? Dallas, TX: Mountain View College, Music Department.

The International Society for Presence Research (2000) 'About presence.' Available at: http://ispr.info/about-presence-2/about-presence/ (Accessed: 23 Sept 2015).

Yin, R. (2003) Case study research: Design and methods. Thousand oaks, CA: SAGE. Submission reference ISSN: 2044-0081 